|| Print ISSN: 2589-7837 || Online ISSN: 2581-3935 ||

International Journal of Medical Science and Diagnosis Research (IJMSDR)

Available Online at www.ijmsdr.com

NLM (National Library of Medicine ID: 101738824)

Original Research Article

Volume 5, Issue 1; January: 2021; Page No. 13-18

\title{
RELATIONSHIP BETWEEN DEPRESSION \& DIABETIC DISTRESS IN ELDERLY TYPE 2 DIABETIC PATIENTS: A STUDY CONDUCTED AT COMMUNITY LEVEL
}

\author{
Dr. Jai Prakash Rai (MBBS)
}

(Deputy Medical Superintendent, BCCL, Dhanbad, Jharkhand)

Distance Education Department, Christian Medical College Vellore, Tamil Nadu, India

Conflicts of Interest: Nil

Corresponding author: Dr. Jai Prakash Rai

DOI: https://doi.org/10.32553/ijmsdr.v5i1.736

\begin{abstract}
:
Background: Depression is common psychiatric illness found in chronic diseases. Diabetes is chronic multi system involvement diseases with associated diabetic distress and depressive symptoms. Patient with diabetes and Depressive disorder has worse health outcome and higher morbidity as well as mortality. Diabetic patients experience some emotional feelings like guilt, denial, stress due to being diabetic and burden of self-care and management in diabetic patients. Depression affecting the treatment modality in diabetics and which led to aggravation of diabetic symptom and so the depression.

Objective: To estimate relationship between depression and diabetic distress in elderly type 2 diabetic patients in Angarpathra hospital, Dhanbad district, Jharkhand, India.

Material and Method: Study is conducted in 150 diabetic patients in rural areas. Demographic, clinical and diabetes related information collected by structured questionnaire. Depression is assessed using PHQ-9(patient health questionnaire).This is standardized questionnaire developed in United States and validated in Indian population.

Results: Depression prevalence in diabetics patients in community is found to be $66 \%$ (mild in 29.3, moderate in $18 \%$, moderately severe $11.3 \%$, severe in $7.3 \%$ ).
\end{abstract}

Keywords: Cross sectional study, Depression, PHQ-9, Diabetic Distress

\section{Introduction:}

Depressive disorders are very common in chronic debilitating condition. Depression is a mood disorder that causes a persistent feeling of sadness and loss of interest. Also called major depressive disorder or clinical depression, it affects how you feel, think and behave and can lead to a variety of emotional and physical problems for at least 2 weeks. You may have trouble doing normal day-to-day activities, and sometimes you may feel as if life isn't worth living [1].

According to the International Diabetes Federation "diabetes is one of the largest global health emergencies of the 21st century" [2]. Numbers are expected to further increase, especially in the urban population, leading to more medical and economic challenges, added on top of the $12 \%$ global health expenditure currently spent on diabetes [2]. Diabetes mellitus (DM) is a chronic endocrine disease resulting due to either failure of the pancreas to produce enough insulin (type 1) or inability of the body to utilize the produced insulin (type 2). Depression defined by the World Health Organization as "a common mental disorder, characterized by sadness, loss of interest or pleasure, feelings of guilt or low self-worth, disturbed sleep or appetite, feelings of tiredness, and poor concentration [3]. Diabetic distress is a emotional state causing emotional distress arising due to living with and burden of self management of diabetes in diabetic patients. There is evidence that the prevalence of depression is moderately increased in prediabetic patients and in undiagnosed diabetic patients, and markedly increased in the previously diagnosed diabetic patients compared to normal glucose metabolism individuals [4]. The prevalence rates of depression could be up to three-times higher in patients with type 1 diabetes and twice as high in people with type 2 diabetes compared with the general population worldwide [5]. On the other hand, 
depression may increase the risk of developing type 2 diabetes with $60 \%$ [6,7]. The National Urban Survey conducted across the metropolitan cities of India reported similar trend: 11.7 per cent in Kolkata (Eastern India) [8].

It seems that there is a bidirectional association between diabetes and depression, a complex relation that might share biological mechanisms, whose understanding could provide a better treatment and improve the outcomes for these pathologies $[9,10]$.

\section{Material and Methods:}

This cross sectional study conducted at Angarpathra hospital, Katras (BCCL) Dhanbad, Jharkhand OPD over a period of 3 months august, September, October, in calendar year 2020 .

A total of 150 diabetic patients were included in study group. This sample size is calculated using Epi info software.

(Details: Epi Info ${ }^{\mathrm{TM}}$, Division of Health Informatics \& Surveillance (DHIS), Center for Surveillance, Epidemiology and Laboratory Services (CSELS)) The prevalence was taken as $18 \%$ based on estimates in previous studies, $[\mathbf{5}, \mathbf{8}]$ with $5 \%$ absolute error, and considering nonresponse rate of $10 \%$ patients to be non-respondents.

\section{Inclusion Criteria}

T2DM patients $>55$ years visiting the OPD who were on treatment for at least 6 months were included in the study.

\section{Exclusion criteria}

(a)(1) Inpatients, (2) patients on corticosteroids therapy, (3) patients with cancer and/or on treatment (chemo or radiotherapy), (4) patients who were on dialysis or awaiting for any major surgery or procedure (coronary artery bypass grafting and amputation) were excluded from the study.

(b) Informed consent obtained from the entire patient under study. Interview conducted using a predesigned, semi-structured questionnaire related to their sociodemographic status, literacy, body

mass index (BMI), the family history of diabetes and depression, the duration of diabetes, occupation and past medical history of diseases and drug intake. Questions were asked in the local language at the time of interview. Haemoglobin A1C level assessment is done to check for their glycaemic control over last 3 months.
The PHQ-9 is the most used and validated screening test for depression in people with diabetes with a high sensitivity and specificity it is used to monitor the severity of depression and response to treatment. However, it can be used to make a tentative diagnosis of depression in at-risk populations - e.g., those with coronary heart disease or after stroke[11,12].

\section{Operational definition:}

PHQ-9 is contain 9 item from full PHQ. If 5 or more than 5 symptoms are there for last fifteen days during most of the day then it is termed as major depression score range from 0-27 and each of the 9 item can be scored from 0 (not at all) to 3 (nearly every days).

\section{If score is}

$0-4=$ no-depression,

5-9=mild depression,

10-14=moderate depression,

$15-19=$ moderately severe depression,

20-27=severe depression.

Then after collection entered in Microsoft excel sheet and analysed using SPSS statistics data editor software version 23. Logistic regression (LR) analysis done by this software to find out the association between selected variables and depression. if $\mathrm{p}$ value $<0.05$ considered as statistically significant.

A positive correlation found (Pearson coefficient $\mathrm{r}=0.898 ; \mathrm{p}<.001)$ between old age (>65year), high HBA1C level illiterate working, windowed/separated female as compared to their counterpart in the study group.

\section{Result:}

The baseline profile of participants are shown in table -1 . Figure -1 shown the depression severity of prevalence in participants [No depression 51, (34\%); mild depression 44, (29.3\%); moderate depression 27 , (18\%); moderate severe depression 17, (11.3\%); severe depression 11, (7.3\%)] with total 99, (66\%) patient are suffering from depression.

Table-2 shows Logistic regression analysis of the predictor of diabetic distress. ODD ratio of diabetic distress was significantly higher for over 65 year of age (3.5X), female (7.7X), illiterate (3.86X), widowed/ separated/ divorced (2.11X), working (1.52X), alcoholic (1.83X), hypothyroidism (2.06xX), uncontrolled diabetics for pronged period [>8\%] $(6.33 \mathrm{X})$, obese $(2.4 \mathrm{X})$ and longer duration diabetes $(1.8 \mathrm{X})$. 
Prevalence of depression in elderly patients $n=150$

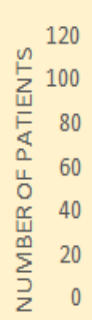

DEPRESSION SEVERITY

\section{Figure 1: prevalence of depression severity in elderly patients}

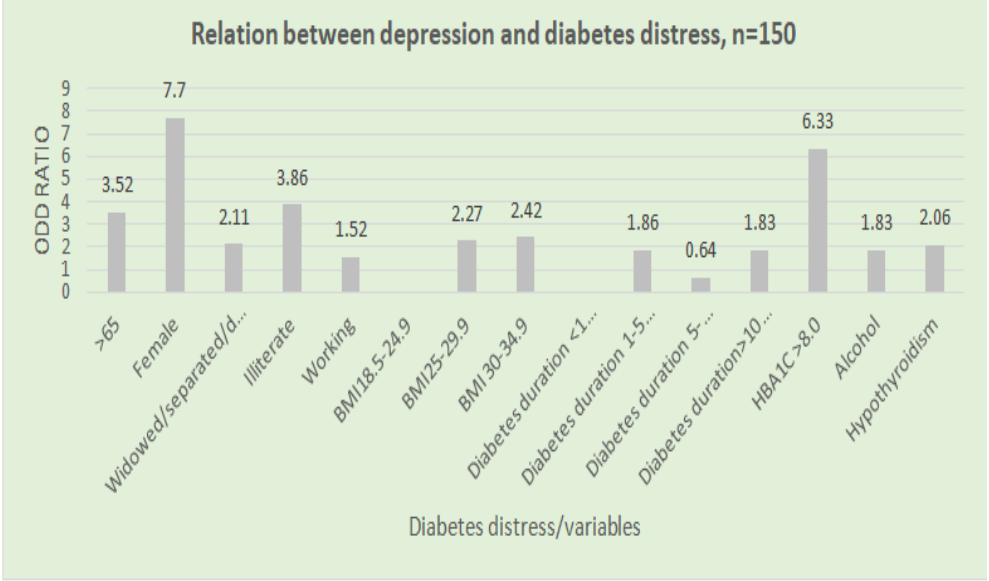

Figure 2: Relationship between depression and diabetes distress in elderly patients

\begin{tabular}{|c|c|}
\hline Diabetic distress & Frequency $n=250 ; n(\%)$ \\
\hline Age mean \pm SD & $62 \pm 6.0$ \\
\hline $55-65$ & $102(68)$ \\
\hline$>65$ & $92(61)$ \\
\hline \multicolumn{2}{|l|}{ Sex } \\
\hline Male & $87(58)$ \\
\hline Female & $77(51)$ \\
\hline \multicolumn{2}{|l|}{ Marital status } \\
\hline Married & $135(90)$ \\
\hline Widowed/separated/divorced & $15(10)$ \\
\hline \multicolumn{2}{|l|}{ Education status } \\
\hline Illiterate & $19(12.6)$ \\
\hline Literate & $131(87.3)$ \\
\hline \multicolumn{2}{|l|}{ Occupation } \\
\hline Working & $87(58)$ \\
\hline Non working & $63(42)$ \\
\hline \multicolumn{2}{|l|}{ Medical condition } \\
\hline Diabetes mellitus & $150(100)$ \\
\hline Hypertension & $139(92.6)$ \\
\hline $\mathrm{BMI}\left(\mathrm{Kg} / \mathrm{m}^{2}\right)$ mean $\pm \mathrm{SD}$ & $26 \pm 2$ \\
\hline $18.5-24.9$ & $57(38)$ \\
\hline $25-29.9$ & $69(46)$ \\
\hline $30-34.9$ & $24(16)$ \\
\hline \multicolumn{2}{|l|}{ Diabetes duration (years) } \\
\hline$<1$ year & $61(40.6)$ \\
\hline $1-5$ year & $49(32.6)$ \\
\hline
\end{tabular}




\begin{tabular}{ll}
\hline Ear & $26(17.3)$ \\
\hline$>10$ year & $14(9.3)$ \\
\hline HBA1C & $122(81.3)$ \\
\hline$<8.0$ & $28(18.6)$ \\
\hline$>8.0$ & $99(66)$ \\
\hline Depression (PHQ-9 score) & $44(29.3)$ \\
\hline Mild (5-9) & $27(18)$ \\
\hline Moderate (10-14) & $17(11.3)$ \\
\hline Moderately Severe (15-19) & $11(7.3)$ \\
\hline severe(20-27) & $71(47.3)$ \\
\hline No depression & \\
\hline Depression duration(years) & $109(72.6)$ \\
\hline$<1$ year & $30(20)$ \\
\hline $1-5$ year & $11(7.3)$ \\
\hline$>5$ year & $87(58)$ \\
\hline Noncompliant & \\
\hline Thyroid function test & $27(18)$ \\
\hline Hyperthyroidism & $54(36)$ \\
\hline Hypothyroidism & $15(10)$ \\
\hline Vitamin B12 Deficiency & $11(7.3)$ \\
\hline Past history of psychiatric illness & $8(5.3)$ \\
\hline Family history of psychiatric illness & \\
\hline Substance abuse & $20(13.3)$ \\
\hline Smoking (yes) & $65(43.3)$ \\
\hline Alcohol (yes ) & \\
\hline & \\
\hline
\end{tabular}

Table 2: Logistic Regression Analysis of Predictor of Diabetic Distress

\begin{tabular}{|c|c|c|c|c|c|c|c|c|}
\hline Diabetic Distress & Frequency $(\mathrm{N}=150)$ & & $\%$ & Depression present & $\begin{array}{l}\text { Depression } \\
\text { absent }\end{array}$ & Odd Ratio & $95 \%$ confidence interval & P value \\
\hline \multicolumn{9}{|l|}{ Age } \\
\hline $55-65$ & 78 & $52 \%$ & & 33 & 45 & & & \\
\hline$>65$ & 72 & $48 \%$ & & 62 & 24 & 3.52 & $1.84,6.75$ & $<.001$ \\
\hline \multicolumn{9}{|l|}{ Sex } \\
\hline Male & 81 & $54 \%$ & & 23 & 58 & & & \\
\hline Female & 69 & $46 \%$ & & 58 & 19 & 7.7 & $3.79,15.63$ & $<.001$ \\
\hline \multicolumn{9}{|l|}{ Marital status } \\
\hline Married & 124 & $83 \%$ & & 76 & 48 & & & \\
\hline $\begin{array}{l}\text { Widowed/separated/ } \\
\text { divorced }\end{array}$ & 26 & $17 \%$ & & 20 & 6 & 2.11 & $0.79,5.62$ & $<.001$ \\
\hline \multicolumn{9}{|l|}{ Education } \\
\hline Illiterate & 29 & $19 \%$ & & 21 & 8 & 3.86 & $1.58,9.41$ & $<.001$ \\
\hline Literate & 121 & $81 \%$ & & 79 & 42 & & & \\
\hline \multicolumn{9}{|l|}{ Occupation } \\
\hline Working & 87 & $58 \%$ & & 57 & 30 & 1.52 & $0.78,2.96$ & $<.001$ \\
\hline Non working & 63 & $42 \%$ & & 35 & 28 & & & \\
\hline \multicolumn{9}{|l|}{$\mathrm{BMI}(\mathrm{Kg} / \mathrm{m} 2)$} \\
\hline $18.5-24.9$ & 42 & $28 \%$ & & 25 & 17 & 2.27 & $0.86,5.96$ & $<.001$ \\
\hline $25-29.9$ & 69 & $46 \%$ & & 40 & 29 & 2.42 & $1,5.86$ & $<.001$ \\
\hline $30-34.9$ & 39 & $26 \%$ & & 30 & 9 & & & \\
\hline \multicolumn{9}{|c|}{ Diabetes duration(years) } \\
\hline$<1$ year & 61 & $41 \%$ & & 35 & 26 & 1.86 & $0.52,6.58$ & $<.001$ \\
\hline $1-5$ year & 49 & $33 \%$ & & 39 & 10 & 0.64 & $0.17,2.48$ & $<.001$ \\
\hline 5-10 year & 26 & $17 \%$ & & 15 & 11 & 1.83 & $0.45,7.41$ & $<.001$ \\
\hline$>10$ year & 14 & $9 \%$ & & 10 & 4 & & & \\
\hline \multicolumn{9}{|l|}{$\overline{\mathrm{HBA} 1 \mathrm{C}}$} \\
\hline$<8.0$ & 28 & $19 \%$ & & 10 & 18 & & & \\
\hline$>8.0$ & 122 & $81 \%$ & & 95 & 27 & 6.33 & $2.62,15.32$ & $<.001$ \\
\hline \multicolumn{9}{|l|}{ Substance abuse } \\
\hline Alcohol & 55 & $37 \%$ & & 38 & 17 & 1.83 & $0.64,5.23$ & $<.001$ \\
\hline Smoking & 20 & $13 \%$ & & 11 & 9 & & & \\
\hline \multicolumn{9}{|l|}{ Thyroid function test } \\
\hline Hypothyroidism & 54 & $36 \%$ & & 20 & 34 & 2.06 & $0.71,5.96$ & $<.001$ \\
\hline Hyperthyroidism & 27 & $18 \%$ & & 6 & 21 & & & \\
\hline
\end{tabular}




\section{Discussion:}

This study was conducted to find out the burden of depression in elderly diabetic patients so that early intervention for depression can be taken, and morbidity as well as mortality can be reduced. Here prevalence of depression is $66 \%$ as compared to $49 \%$ found in other studies. (Madhu et. al. reported the prevalence of depression $49 \%$ amongst subjects with diabetes in Trivandrum, India) [13].

Ageing is a risk factor for development of depression here person $>65$ years age are 3.5 times more at risk for depressive symptom than person between 55-65 years of age. As person getting older there are many comorbid conditions that further aggravate the likelihood of depressive symptom to develop.

Illiterates are 3.8 times more prone for depression. This is also proven by the fact that those with higher levels of education, tend to have fewer depressive symptoms [14].

Person with uncontrolled blood sugar $(\mathrm{HBA} 1 \mathrm{C}>8$ ) for long period are 6.3 times more at risk of developing the depressive disorders. This is supported by the fact that those with higher levels of education tend to have fewer depressive symptoms. Siddiqui et. al. found that there is a higher prevalence of depression in patients with type 2 diabetes was almost twice as high compared to those without diabetes in Delhi [15].

Widowed separated divorced person are two times increased at risk of depression in old age. The effects of marriage on depressive symptoms in men and women may be different, with lower levels of depressive symptoms in married men, compared with unmarried men, but similar rates in married women, compared with unmarried women. Dissatisfaction with their partner was uncommon, but highly associated with depressive symptoms [16].

Obesity in elderly patients above 65 years are associated with 2.4 times more increased risk of depressive symptoms as obesity itself mother of many non- communicable chronic diseases which make person susceptible further for depressive symptoms. There is a positive relationship between depression and obesity [17].

Working person in this study 1.5 times more at increased risk of depressive symptom at old age for earning than non working persons. According to a Monster's 2020 State of the Candidate survey of 1,000 full-time and part-time employees in the United States, many employees have experienced depression (24\%) and physical illness (12\%) as a result of their job; $34 \%$ said their job negatively affects their mental health [18].

Hypothyroid patients are 2 times more at risk of depressive symptom than hyperthyroid patients at old age. Hypothyroid patients frequently demonstrate features of depression, cognitive dysfunction, apathy, and psychomotor slowing. In severe forms of hypothyroidism, clinical symptoms may mimic that of melancholic depression and dementia [19].

In older men, the association between time lived with the diagnosis of diabetes and the risk of depression is 'J-shaped'. Frailty mediates some of the association between diabetes and depression, although other unmeasured factors are also likely to play a role [20].

Vitamin B12 deficiency had a risk of depression that was more than twice as high as that of women without vitamin B12 deficiency. The higher risk was apparent for severe depression but not for mild depression. No association with depression was found for metabolically significant folate deficiency[21].

Alcoholic are 1.8 times more at risk of depressive symptom at old aged persons. Alcohol abuse brings with it a bevy of negative effects on virtually every aspect of life. As a person begins to experience financial and career consequences as a result of alcohol abuse, and their relationships begin to suffer, their depression worsens. This often leads to a damaging cycle of abusing alcohol in an effort to selfmedicate symptoms of depression, and the depression worsening due to the continued alcohol abuse [22].

\section{Conclusion:}

Depression has negative aftermath on diabetes and diabetes complicates further the depression so a vicious cycle form. These both problems are growing in elderly population and has both worse outcomes altogether on geriatric population. Relationship between diabetes and depression is strong, as appears in this study. There is $66 \%$ people with depression in elderly type 2 diabetes patients with many diabetic distress determinants like age>65year, female sex, single, windowed/separated/divorced, hypothyroidism, obesity, alcoholism, diabetes duration, high HBA1C. So early diagnosis and treatment of depression in geriatric population should be promoted.

\section{References}

1. https://www.mayoclinic.org/diseasesconditions/depression/symptoms-causes/syc20356007 
2. International Diabetes Federation. IDF Diabetes. 7 ed. Brussels, Belgium: International Diabetes Federation; 2015. http://www.diabetesatlas.org.

3. Marcus M, Yasamy MT, van Ommeren, M, Chisholm D, Saxena S. Depression: A global public health concern. Geneva, Switzerland: WHO Department of Mental Health and Substance Abuse; 2012. Available from: http://www.who.int/mental_health/manag ement/depression/who_paper_depression_wfmh 2012.pdf. [Last cited on 2017 Jul 18].

4. Chen S, Zhang Q, Dai G, Hu J, Zhu C, Su L, Wu X. Association of depression with prediabetes, undiagnosed diabetes, and previously diagnosed diabetes: a meta-analysis. Endocrine. 2016

5. Roy T, Lloyd CE. Epidemiology of depression and diabetes: a systematic review. J Affect Disord. 2012;142(Suppl):S8-S21.

6. Mezuk B, Eaton WW, Albrecht S, Golden SH. Depression and type 2 diabetes over the lifespan: a meta-analysis. Diabetes Care. 2008; 31:2383-2390.

7. Rubin RR, Ma Y, Marrero DG, Peyrot M, Barrett-Connor EL, Kahn SE, Haffner SM, Price DW, Knowler WC. Elevated depression symptoms, antidepressant medicine use, and risk of developing diabetes during the diabetes prevention program. Diabetes Care. 2008; 31: 420-426.

8. Prevalence of diabetes and other health related problems across India and worldwide: An overview. Journal of Applied and Natural Science 8 (1): 500 - 505 (2016)

9. Berge LI, Riise T. Comorbidity between Type 2 Diabetes and Depression in the Adult Population: Directions of the Association and Its Possible Pathophysiological Mechanisms. Int J Endocrinol. 2015;2015:164760.

10. Moulton CD, Pickup JC, Ismail K. The link between depression and diabetes: the search for shared mechanisms. Lancet Diabetes Endocrinol. 2015;3:461-471.

11. Haddad M, Walters $\mathrm{P}$, Phillips $\mathrm{R}$, et al; Detecting depression in patients with coronary heart disease: a diagnostic evaluation of the PHQ-9 and HADS-D in primary care, findings from the UPBEAT-UK study. PLoS One. 2013 Oct 108(10):e78493. doi:10.1371/journal. pone. 0078493.

12. De Man-van Ginkel JM, Gooskens F, Schepers VP, et al; Screening for poststroke depression using the patient health questionnaire. Nurs Res. 2012 Sep-Oct 61(5):333-41.

13. Madhu M, Abish A, Anu K, et al. Predictors of depression among patients with diabetes mellitus in Southern India. Asian J Psychiatr 2013; 6:313-7

14. Miech RA, Eaton WW, Brennan K. Mental health disparities across education and sex: A prospective analysis examining how they persist over the life course. J Gerontol BPyschol. 2005;60:S93-S98.

15. Siddiqui $S$, Jha $S$, Waghdhare $S$, et al. Prevalence of depression in patients with type 2 diabetes attending an outpatient clinic in India. Postgrad Med J 2014; 90:552-6.

16. Philip Donald St John. Marital Status, Partner Satisfaction, and Depressive Symptoms in Older Men and Women. La Revue canadienne de psychiatrie, vol 54, no 7, juillet 2009;487492

17. De Wit L, Luppino F, van Straten A, Penninx B, Zitman F, et al. (2010) Depression and obesity: a meta-analysis of community-based studies. Psychiatry Res 178:230-235.

18. https://www.monster.com/careeradvice/article/depression-at-work

19. Whybrow PC, Prange AJ, Jr., Treadway CR. Mental changes accompanying thyroid gland dysfunction. A reappraisal using objective psychological measurement. Archives of General Psychiatry. 1969; 20 (1):48-63.

20. Osvaldo P Almeida et.al.Duration of diabetes and its association with depression in later life: The Health In Men Study (HIMS). PMID: 26921921 DOI: 10.1016/j.maturitas.2016.01. 003

21. Brenda W.J.H. Penninx et.al. Vitamin B12 Deficiency and Depression in Physically Disabled Older Women: Epidemiologic Evidence From the Women's Health and Aging Study. American J Psychiatr 2000; 5:715-721

22. https://americanaddictioncenters.org/alcoholism -treatment/depression 